\title{
BMJ Open Epidemiological investigation of the first 5685 cases of SARS-CoV-2 infection in Qatar, 28 February-18 April 2020
}

Hanan M Al Kuwari, ${ }^{1}$ Hanan F Abdul Rahim, ${ }^{2}$ Laith J Abu-Raddad (D) , ${ }^{3}$ Abdul-Badi Abou-Samra, ${ }^{4}$ Zaina Al Kanaani, ${ }^{5}$ Abdullatif Al Khal, ${ }^{4}$ Einas Al Kuwari, ${ }^{6}$ Salih Al Marri, ${ }^{1}$ Muna Al Masalmani, ${ }^{4}$ Hamad E Al Romaihi, ${ }^{1}$ Mohamed H Al Thani, ${ }^{1}$ Peter V Coyle, ${ }^{6}$ Ali N Latif, ${ }^{5}$ Robert Owen, ${ }^{7}$ Roberto Bertollini, ${ }^{1}$ Adeel Ajwad Butt (D) 4,8

To cite: Al Kuwari HM, Abdul Rahim HF, Abu-Raddad LJ, et al. Epidemiological investigation of the first 5685 cases of SARS-CoV-2 infection in Qatar, 28 February-18 April 2020. BMJ Open 2020;10:e040428. doi:10.1136/ bmjopen-2020-040428

- Prepublication history and additional material for this paper are available online. To view these files, please visit the journal online (http://dx.doi. org/10.1136/bmjopen-2020040428).

Received 14 May 2020

Revised 03 September 2020

Accepted 08 September 2020

Check for updates

(C) Author(s) (or their employer(s)) 2020. Re-use permitted under CC BY-NC. No commercial re-use. See rights and permissions. Published by BMJ.

For numbered affiliations see end of article.

Correspondence to Professor Adeel Ajwad Butt; aabutt@hamad.qa

\section{ABSTRACT}

Objective To define the epidemiological curve of COVID-19 in Qatar and determine factors associated with severe or critical illness.

Design Case series of first 5685 COVID-19 cases in Qatar. Setting and participants All confirmed COVID-19 cases in the State of Qatar between 28 February and 18 April 2020.

Main outcome measures Number of total and daily new COVID-19 infections; demographic characteristics and comorbidity burden and severity of infection; factors associated with severe or critical illness.

Results Between 28 February and 18 April 2020, 5685 cases of COVID-19 were identified. Median age was 34 (IQR 28-43) years, $88.9 \%$ were male and $8.7 \%$ were Qatari nationals. Overall, $83.6 \%$ had no concomitant comorbidity, and $3.0 \%$ had three or more comorbidities. The overwhelming majority (90.9\%) were asymptomatic or with minimal symptoms, with $2.0 \%$ having severe or critical illness. Seven deaths were observed during the time interval studied. Presence of hypertension or diabetes was associated with a higher risk of severe or critical illness, but age was not. The epidemiological curve indicated two distinct patterns of infection, a larger cluster among expatriate craft and manual workers and a smaller one among Qatari nationals returning from abroad during the epidemic.

Conclusion COVID-19 infections in Qatar started in two distinct clusters, but then became more widespread in the population through community transmission. Infections were mostly asymptomatic or with minimal symptoms and associated with very low mortality. Severe/critical illness was associated with presence of hypertension or diabetes but not with increasing age.

\section{INTRODUCTION}

A cluster of patients with pneumonia of unknown aetiology linked to a seafood wholesale market was first reported from Wuhan, China, in December 2019. ${ }^{1-4}$ A novel coronavirus, SARS-CoV-2 was isolated as the causative organism, and the resultant disease was named COVID-19. ${ }^{15}$ Initially presumed to

\section{Strengths and limitations of this study}

- National study with unified contact tracing and testing.

- All testing done at a single lab and all tests performed in the State of Qatar during the study period were included, providing a robust national estimate of the number of infected persons among those tested.

- Comorbidities were retrieved from the electronic medical records using International Classification of Diseases 10th edition, Australian Modification codes.

- Exact geographic location and contact tracing data were not included in the current report.

- It is possible that some persons still under care on the study end date may have progressed to more severe disease after that date.

be transmitted from animals to humans, the virus has since spread quickly across the globe through human-to-human transmission. ${ }^{6-9}$ As of 20 August 2020, more than 22 million cases and over 791000 deaths have been reported globally. Published epidemiological studies across a number of populations show significant differences in rates and severity of infection and in case fatality rates. ${ }^{10}$ At this stage of a novel virus pandemic, analysing transmission patterns in populations with unique demographic characteristics can add to our understanding of the disease dynamics. While it is difficult to isolate the effects of public health measures such as quarantine, lockdown and physical distancing, it is nevertheless useful to track the course of the epidemic in relation to the timeline of their implementation for an understanding of the context in which the epidemic unfolded.

Qatar is a part of the six-country Gulf Cooperation Council (GCC), which also includes 
Saudi Arabia, Kuwait, Oman, Bahrain and the United Arab Emirates. Qatar has a unique population demographic profile. Among the 2.8 million residents of Qatar, expatriate workforce constitutes about $88 \%$ of the population. ${ }^{11}$ Due to the nature of the expatriate workforce, the majority of the population in Qatar $(\sim 75 \%)$ are male, and the population pyramid is heavily concentrated in the 20-50year age groups, particularly among males. ${ }^{11}$ There is evidence that COVID-19 disproportionally affects males, and outcomes are poorer in the older age group. ${ }^{312} 13$ Influx or efflux of the population can also affect epidemic dynamics. Such changes in population can be expected in populations with a high proportion of non-national or non-native groups such as GCC countries. There were no travel restrictions in the early part of the study, that is, from 28 February to 30 March 2020. A general restriction on all incoming flights into Qatar was implemented on $31 \mathrm{March}$, which halted almost all influx of visitors or residents into the country. Exit travel was not generally restricted. However, two factors diminished outbound travel sharply: (1) global restrictions on travel leading to a sharp reduction in all flights; and (2) restriction of essential workers, for example, healthcare workers, from taking leave and travelling except in urgent or emergency situations. Our main objective was to define the epidemiological features of COVID-19 in Qatar and to determine factors associated with severe or critical illness. Understanding the epidemiology and risk factors for serious infection in Qatar will be important in understanding the epidemiology in countries with unique demographic characteristics.

\section{METHODS}

Even before the first case of COVID-19 was identified in the country, Qatar had instituted extensive plans to identify and manage persons with COVID-19 infection. The existing tracking, tracing and identification mechanism within the Ministry of Public Health, with proven effectiveness during the Middle East respiratory syndrome coronavirus outbreak, was expanded and put on alert. ${ }^{145}$ Testing for suspected cases started on 5 February 2020, and the first case was recorded on 28 February 2020. Using the Ministry of Public Health national database of patients with COVID-19, we retrospectively identified all confirmed cases of COVID-19 infection between 28 February 2020 and 18 April 2020. All COVID-19 testing in Qatar was performed at the central laboratory of Hamad Medical Corporation, which is the public healthcare delivery arm for the State of Qatar and provides over $85 \%$ of the inpatient bed capacity in the State. During the study period, there was targeted, purposeful testing of persons presenting with symptoms of influenza-like illness suggesting COVID-19. For every person who tested positive, active and aggressive contact tracing was carried out by trained staff at the Ministry of Public Health. Nasopharyngeal and throat swabs were collected from suspected cases with symptoms of influenza-like illness suggesting
COVID-19 and, if confirmed, from close contacts. Close contacts were identified based on the criteria published by the US Centers for Disease Control and Prevention, which defines a close contact as 'any individual who was within 6 feet of an infected person for at least 15 minutes starting from 2 days before illness onset (or, for asymptomatic patients, 2 days prior to positive specimen collection) until the time the patient is isolated' ${ }^{16}$ Real-time RT-PCR was used to detect SARS-CoV-2 infection using TaqPath COVID-19 Combo Kit (Thermo Fisher Scientific, Waltham, Massachusetts, USA) or Cobas SARS-CoV-2 Test (Roche Diagnostics, Rotkreuz, Switzerland). These tests are highly sensitive and specific with no cross-reactivity against multiple other respiratory viruses. ${ }^{17} 18$ Nationality of each tested person was ascertained from the official State Identification Card, which is issued to each national and expatriate worker and their dependents residing in Qatar. Demographic characteristics and comorbidities were retrieved from the electronic medical records where they are coded using the International Classification of Diseases 10th edition, Australian Modification (ICD-10 AM). Severity of illness at the time of presentation was determined by expert coders using criteria suggested by the WHO, including admission to an acute care or an intensive care bed, need for mechanical ventilation, oxygen saturation and supplemental oxygen requirement $^{19}$ (see online supplemental table 1 ). Severity of illness was categorised into: (1) asymptomatic or minimal symptoms, (2) mild symptoms or uncomplicated upper respiratory tract infection without clinical or radiographic evidence of pneumonia, (3) mild symptoms with clinical or radiographic evidence of pneumonia, (4) severely ill and (5) critically ill. ${ }^{19}$

We created a timeline of newly diagnosed cases to study the progression of the epidemic in Qatar. Key governmental decisions taken by the Supreme Committee for Crisis Management and the Council of Ministers in response to the epidemic were marked on the timeline to show their temporal relation to the cases. Multivariable logistic regression was used to determine factors associated with severe and critical illness. Covariates of interest included in the model were age, gender, nationality and presence of comorbidities. Comorbidities with a total count of less than 15 were excluded because of the small numbers.

Changes in population movement were assessed using Google mobility reports, a publicly available tool that tracks movement of people who use mobile applications like Google Maps. ${ }^{20}$ They show changes in visits and length of stay at various locations compared with a baseline. Baseline was the median value, for the corresponding day of the week, during the 5 -week period between 3 January 2020 and 6 February 2020. ${ }^{20}$

\section{Patient and public involvement}

This study was conducted in response to a national and global public health emergency. There was no patient or 
public involvement. However, key elements of the data are shared with the public on a daily basis.

\section{RESULTS}

Between 5 February 2020 and 18 April 2020 (11:00 local time), 60645 persons were tested for SARS-CoV-2, of whom 5685 were confirmed positive. Before the first case was diagnosed, testing for SARS-CoV-2 focused on those with influenza-like illness and severe acute respiratory infection. The first cases were identified among quarantined travellers returning to Qatar on 28 February 2020, followed by the identification of a large cluster of over 300 infections on 6 March 2020 among expatriate craft and manual workers. Following the discovery of the first community cluster, testing was expanded to include contacts of new cases, persons in hotspots, that is, areas where infections were diagnosed, individuals with suspected infection or suggestive symptoms and travellers coming or returning to Doha. The rapid expansion of testing created a backlog, which was resolved through an investment in testing infrastructure that significantly increased the testing capacity to approximately 4000 tests per day in the early days of the pandemic.

The number of new cases diagnosed by date of diagnosis is presented in figure 1 . The epidemiological curve showed two distinct patterns of infection transmission. A larger and sustained community transmission was observed among expatriate workers, predominantly among craft and manual workers, which subsequently reached other population segments. A second smaller cluster among Qatari nationals returning from overseas during the study period was not sustained over time. Subsequent smaller case clusters among Qatari nationals were traced to the local community. The number of tests performed per day and the number testing positive are provided in online supplemental figure 1 . The positivity rate, that is, number of tests positive over total number of tests, is shown in figure 2 . The positivity rate increased steadily with time, with somewhat of an accelerated rate after 5 April 2020.

The median age (IQR) of the infected persons was $34(28-43)$ years and $88.9 \%$ were male (table 1$)$. Other baseline characteristics are also shown in table 1 . The nationalities with highest frequency of infection were Indian (27.4\%), Bangladeshi (18.9\%), Nepalese (18.4\%), Qatari (8.7\%) and Pakistani (6.2\%). The most common comorbidities were hypertension (6.9\%), diabetes mellitus $(6.0 \%)$, cardiovascular disease $(4.4 \%)$ and chronic lung disease $(3.0 \%)$. Comorbidity data were missing for 235 persons (4.1\%). Among all infected persons, $4753(83.6 \%)$ had no known comorbidity and $697(12.3 \%)$ had at least one comorbidity. An overwhelming majority of infected persons $(90.9 \%)$ were either asymptomatic or had minimal symptoms, $0.8 \%$ had mild illness without evidence of pneumonia, 2.3\% had mild illness with pneumonia and $2 \%$ were severe or critically ill. Severity of illness data were missing for 223
$(3.9 \%)$ persons (table 1$)$. Since age is a critical determinant of outcomes in patients with SARS-CoV-2 infection, we looked at age with multiple different groupings and ranges. Among those aged 0-10, only 3 out of 121 children had mild upper respiratory symptoms without evidence of pneumonia; all others were asymptomatic. Among those aged 11-15 years, none of the 44 children were symptomatic. Among those aged 16-18 years, one had mild upper respiratory symptoms without evidence of pneumonia and two had severe disease. There were no incidence of critical illness and no deaths in children. These numbers were too low for each of those age categories to be entered into a regression model; therefore, we grouped ages $0-20$ years together.

A larger proportion of persons with mild illness with or without pneumonia and those with severe or critical illness had at least one comorbidity (table 2). Compared with those with asymptomatic or minimally symptomatic illness, prevalence of most comorbidities was three to four times higher among those with mild disease with or without pneumonia or severe/critical illness. Severity of illness by number of comorbidities is shown in table 3 . Among persons with no comorbidity, $96.1 \%$ were asymptomatic or had minimal symptoms, $2.5 \%$ had mild illness with or without pneumonia and $1.4 \%$ were severely or critical ill. Among persons with two or more comorbidities, $82.1 \%$ were asymptomatic or had minimal symptoms, $10.9 \%$ had mild illness with or without pneumonia and $7.1 \%$ were severely or critical ill (table 3 ).

Seven deaths were observed during the time interval studied, corresponding to a case-fatality rate of 1.2 per 1000 cases. All seven deaths were males aged 40-88 years. All except one (74-year-old man) had comorbidities, including diabetes (five subjects), cardiovascular disease (five subjects) and hypertension (three subjects). One patient (58-year-old man) had five comorbidities (diabetes, hypertension, cardiovascular disease, chronic kidney and liver disease). In a multivariable logistic regression model, presence of hypertension (OR 3.49; 95\% CI 1.83 to 6.68 ) or diabetes (OR 3.17; 95\% CI 1.76 to 5.71) were associated with a higher risk of severe or critical disease (table 4). Cardiovascular disease, chronic lung disease, chronic kidney disease and solid organ malignancy were not associated with a higher risk. We repeated the logistic regression analysis after excluding those with missing data and the results were nearly identical (see online supplemental table 2). We also repeated the analysis using number of comorbidities as covariates. Presence of any single comorbidity (OR 5.43, 95\% CI 3.41 to 8.63 ) or any three or more comorbidities (OR $6.16,95 \%$ CI 3.35 to 11.32 ) were associated with a higher risk of severe or critical illness (see online supplemental table 3).

In a subsequent report in which the first 5000 patients with COVID-19 infection in Qatar were followed for up to 60 days after diagnosis, a total of 1424 patients (28.5\%) required hospitalisation, out of which $108(7.6 \%)$ were admitted to an intensive care unit (ICU), 14 patients 


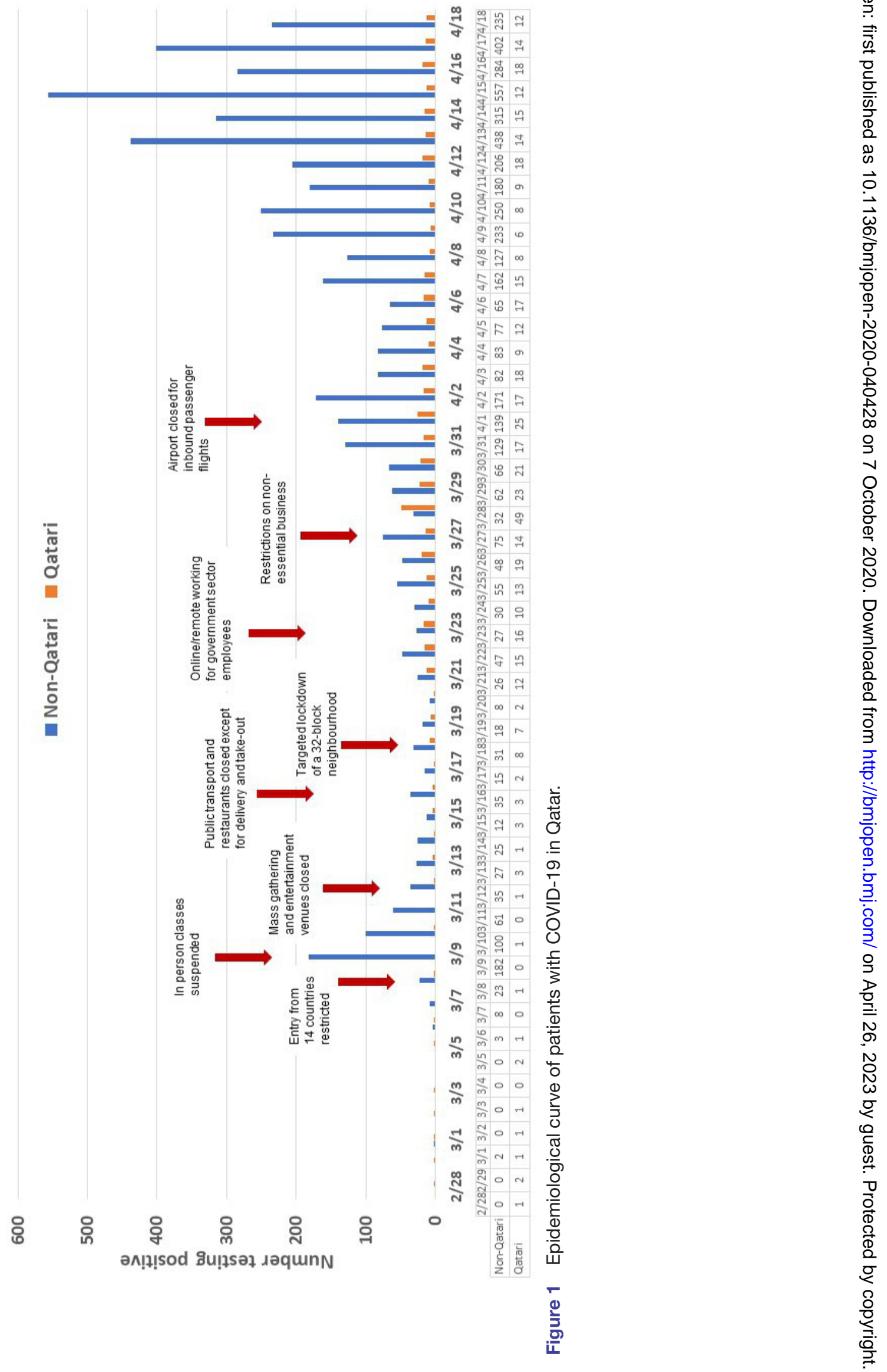




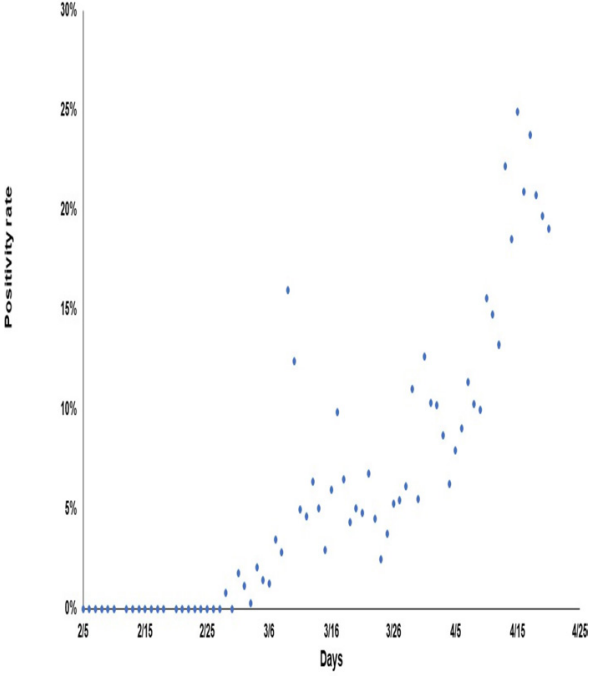

Figure 2 Positivity rate among those tested for SARSCoV-2 active infection by swab day.

$(0.28 \%)$ had died, $10(0.2 \%)$ were still in hospital and 2 $(0.04 \%)$ were still in ICU. ${ }^{21}$

Google mobility reports data demonstrated a significant decrease in number of people visiting retail and recreation outlets, grocery and pharmacy stores, parks, transit stations and workplaces over time (table 5). A concurrent increase in people staying in residential areas was observed over this timeframe. A snapshot on 17 April showed a $69 \%$ reduction in visits to retail and recreation areas, a $44 \%$ reduction in visits to grocery and pharmacy stores, a $64 \%$ decrease in visits to parks, a $68 \%$ decrease in visits to transit stations and a $38 \%$ decrease in visits to workplaces. A $21 \%$ increase in people in residential areas was observed on this date.

\section{DISCUSSION}

We provide a characterisation of the SARS-CoV-2 outbreak in Qatar, which offers new insights into the behaviour of the pandemic in a unique demographic setting.

The first case in Qatar was identified on 28 Februa 2020, among returning travellers, which is nearly 9 weeks after the first cluster was reported from Wuhan, China. ${ }^{22}$ During this time, infection had spread to multiple countries over four continents. This was also a critical time during which the State of Qatar formulated a national plan to respond to the anticipated cases. Testing for SARS-CoV-2 started in Qatar on 5 February 2020 and the first major cluster of cases was identified on 8 March 2020 where over 300 cases were linked to four expatriate workers through aggressive contact tracing. Such aggressive identification and contact tracing and testing were probably the reasons for a small number of daily new cases until 31 March 2020. At that time, a large number of returning travellers and nationals were identified to have infection. The number of daily diagnosed infections accelerated in April, in part due to a large increase in number of daily tests and also reflecting expansion of the epidemic in the
Table 1 Characteristics of 5685 patients with confirmed COVID-19 infection in Qatar between 29 February and 18 April 2020

\begin{tabular}{|c|c|}
\hline Variable & n (\%) \\
\hline \multicolumn{2}{|l|}{ Demographics } \\
\hline Mean age, years (SD) & $35.8(12.0)$ \\
\hline Median age, years (IQR) & $34(28-43)$ \\
\hline 0-20 years & $302(5.3)$ \\
\hline $21-40$ years & $3666(64.5)$ \\
\hline $41-60$ years & $1537(27.0)$ \\
\hline$>60$ years & $180(3.2)$ \\
\hline Male sex & $5052(88.9)$ \\
\hline \multicolumn{2}{|l|}{ Nationality } \\
\hline Indian & $1559(27.4)$ \\
\hline Bangladeshi & 1077 (18.9) \\
\hline Nepalese & $1047(18.4)$ \\
\hline Qatari & $497(8.7)$ \\
\hline Pakistani & $353(6.2)$ \\
\hline Filipino & $185(3.3)$ \\
\hline Egyptian & $179(3.1)$ \\
\hline Sri Lankan & 109 (1.9) \\
\hline Sudanese & $91(1.6)$ \\
\hline Others & $588(10.3)$ \\
\hline \multicolumn{2}{|l|}{ Comorbidities } \\
\hline Hypertension & $391(6.9)$ \\
\hline Diabetes mellitus & $344(6.0)$ \\
\hline Cardiovascular disease & $250(4.4)$ \\
\hline Chronic lung disease & $169(3.0)$ \\
\hline Chronic kidney disease & $35(0.6)$ \\
\hline Solid organ malignancy & $30(0.5)$ \\
\hline Tuberculosis & $13(0.2)$ \\
\hline Chronic liver disease & $12(0.2)$ \\
\hline Autoimmune disease & $6(0.1)$ \\
\hline Missing & $235(4.1)$ \\
\hline \multicolumn{2}{|l|}{ Number of comorbidities (235 missing) } \\
\hline 0 & $4753(83.6)$ \\
\hline 1 & $384(6.8)$ \\
\hline 2 & $139(2.5)$ \\
\hline 3 & $121(2.1)$ \\
\hline$\geq 4$ & $53(0.9)$ \\
\hline Missing & $235(4.1)$ \\
\hline \multicolumn{2}{|l|}{ Severity of illness } \\
\hline Asymptomatic or minimal symptoms & $5168(90.9)$ \\
\hline Mild illness without pneumonia & $44(0.8)$ \\
\hline Mild illness with pneumonia & $133(2.3)$ \\
\hline Severe illness & $82(1.4)$ \\
\hline Critical illness & $35(0.6)$ \\
\hline Missing & $223(3.9)$ \\
\hline
\end{tabular}


Table 2 Prevalence of comorbidities by severity of illness

\begin{tabular}{llll}
\hline & $\begin{array}{l}\text { Asymptomatic or minimally } \\
\text { symptomatic, } \mathbf{n}(\%)\end{array}$ & $\begin{array}{l}\text { Mild illness with or without pneumonia, } \\
\mathbf{n}(\%)\end{array}$ & $\begin{array}{l}\text { Severe/critical illness, } \\
\mathbf{n}(\%)\end{array}$ \\
\hline Hypertension & $317(6.1)$ & $41(23.2)$ & $31(26.5)$ \\
Diabetes mellitus & $281(5.4)$ & $33(18.6)$ & $30(25.6)$ \\
Cardiovascular disease & $199(3.8)$ & $31(17.5)$ & $19(16.2)$ \\
Chronic lung disease & $145(2.8)$ & $12(6.8)$ & $4(3.6)$ \\
Chronic kidney disease & $25(0.5)$ & $6(3.4)$ & $2(1.7)$ \\
Solid organ malignancy & $26(0.5)$ & $2(1.1)$ & $1(0.8)$ \\
Tuberculosis & $10(0.2)$ & $2(1.1)$ & $0(0)$ \\
Chronic liver disease & $10(0.2)$ & $2(1.1)$ & $0(0)$ \\
\hline Autoimmune disease & $5(0.1)$ & $1(0.6)$ & \\
\hline
\end{tabular}

wider population. This trend occurred predominantly in expatriate workers often living in more crowded areas and accommodations with frequent social mixing despite a national campaign to discourage people's movement except in urgent situations. The epidemic, however, eventually reached a larger population.

An overwhelming majority $(>90 \%)$ of confirmed COVID-19 cases were asymptomatic or had minimal symptoms not requiring urgent medical care or hospitalisation. This is likely due to the younger age of the population (median age 34 years) and overall absence of any comorbidities in the vast majority of the infected persons. This reinforces our current understanding of the disease being mild or asymptomatic in a majority of the persons, particularly among the younger and healthier persons, as well as the strong role of age in the epidemiology of this infection. Similar to other studies, presence of comorbidities was associated with severe or critical disease. ${ }^{1} \mathrm{We}$ found a very low mortality among confirmed patients with COVID-19 in Qatar, which may at least partly be attributable both to the timely and effective response of the health system and the demographic characteristics of the infected persons. It is conceivable that right censoring with the time delay between onset of disease to death may play a part, though similarly very low mortality after the study period ended does not support this. The role that factors, such as free access to high-quality medical care for everyone residing in Qatar, availability of a high number of critical care beds or differences in viral subtypes, played needs further study.

In response to the spread of COVID-19, the country took a series of public health measures, including limiting incoming passenger flights into Doha through Hamad
International Airport and providing free state quarantine facilities for returning travellers. A host of other measures were implemented gradually that promoted physical distancing, including closing retail stores in malls and shopping centres, closing entertainment and dining facilities, postponing or cancelling large sports events and conferences, suspending classes in schools and universities and mandating working from home for $80 \%$ of workers in the public and private sectors. The healthcare system was also reorganised to prioritise COVID-19 response over routine services. All positive cases including those without symptoms were admitted to isolation facilities managed by the public healthcare system. These public health measures were heavily promoted and widely communicated through social and traditional media outlets to all segments of society. Mobility data show a significant reduction in visits to common retail, recreation, transit and workplace areas, which may have contributed to a reduction in spread of infection. There was a more pronounced reduction in mobility in the weeks following 5 April, which coincides with the significant rise in the reported number of positive cases.

The pandemic has affected nearly every country and territory in the world. However, infection rates and case fatality rates vary widely among countries. For example, crude case fatality rate is $3.2 \%$ in the USA, $7.5 \%$ in Canada, $15 \%$ in the UK, but only $0.16 \%$ in Qatar and $0.67 \%$ in Kuwait (as of 10 August 2020). ${ }^{23}$ It has been postulated that the population demographics and comorbidity burden are the key determinants of the variability in case fatality rates. However, these differences alone are unlikely to fully account for the widely variable case fatality rates. Testing per capita, seroprevalence among

Table 3 Severity of illness by number of comorbidities

\begin{tabular}{|c|c|c|c|}
\hline Number of comorbidities & $\begin{array}{l}\text { Asymptomatic or minimal } \\
\text { symptoms, } \mathrm{n}(\%)\end{array}$ & $\begin{array}{l}\text { Mild illness with or without } \\
\text { pneumonia, n (\%) }\end{array}$ & $\begin{array}{l}\text { Severe/critical } \\
\text { illness, n (\%) }\end{array}$ \\
\hline No comorbidity & $4582(96.1)$ & $120(2.5)$ & $67(1.4)$ \\
\hline Two or more comorbidities & $256(82.1)$ & 34 (10.9) & $22(7.1)$ \\
\hline
\end{tabular}


Table 4 Factors associated with severe or critical illness (multivariable logistic regression model)

\begin{tabular}{|c|c|c|c|}
\hline Variables & OR & $95 \% \mathrm{Cl}$ & $P$ value \\
\hline \multicolumn{4}{|l|}{ Age (years) } \\
\hline 0-20 (reference) & Reference & & \\
\hline $21-40$ & 1.51 & 0.46 to 4.93 & 0.62 \\
\hline $41-60$ & 1.57 & 0.45 to 5.46 & 0.55 \\
\hline $60+$ & 1.39 & 0.3 to 6.49 & 0.94 \\
\hline Male gender & 0.98 & 0.53 to 1.83 & 0.95 \\
\hline $\begin{array}{l}\text { Qatari nationality } \\
\text { (vs non-Qatari) }\end{array}$ & 0.83 & 0.43 to 1.6 & 0.58 \\
\hline Hypertension & 3.49 & 1.83 to 6.68 & 0.0002 \\
\hline Diabetes mellitus & 3.17 & 1.76 to 5.71 & 0.0001 \\
\hline $\begin{array}{l}\text { Cardiovascular } \\
\text { disease }\end{array}$ & 0.54 & 0.24 to 1.22 & 0.14 \\
\hline Chronic lung disease & 1.64 & 0.79 to 3.42 & 0.19 \\
\hline $\begin{array}{l}\text { Chronic kidney } \\
\text { disease }\end{array}$ & 1.31 & 0.41 to 4.21 & 0.65 \\
\hline Cancer & 1.26 & 0.28 to 5.66 & 0.77 \\
\hline
\end{tabular}

the general population, availability of acute and intensive care beds, living arrangements of infected persons and access to promising therapeutic options may provide additional explanations for the difference.

Strengths of our study include unified contact tracing and testing, with all testing done at a single lab. All tests performed in the State of Qatar were included, providing a robust national estimate of the number of infected persons among those tested. There are limitations to our study. Comorbidities were retrieved from the electronic medical records using ICD-10 AM codes. Exact geographic location and contact tracing data were not included in the current report. Our study end date was 18 April 2020, and all persons with confirmed infection until that date were included. However, it is possible that some persons may have progressed to more severe disease after this date. Some of these data are the subject of another report with a brief summary provided in the preceding paragraph. Finally, the testing for COVID-19 during the study period was not population based, which may affect the true infection rates and outcomes.
In conclusion, we describe the evolution of COVID-19 epidemic in the State of Qatar. For the population tested, the epidemic predominantly affected males and younger population and was associated with no or minimal symptoms in a vast majority of the infected persons. Presence of hypertension and diabetes were associated, but increasing age was not associated with a higher risk of severe or critical illness. Public health measures were instituted early and may have led to the slower growth compared with other countries that delayed such measures.

\section{Author affiliations}

${ }^{1}$ Office of the Minister of Public Health, Ministry of Public Health, Doha, Qatar ${ }^{2}$ College of Health Sciences, QU Health, Qatar University, Doha, Qatar ${ }^{3}$ Infectious Disease Epidemiology Group, Weill Cornell Medicine-Qatar, Cornell University, Doha, Qatar

${ }^{4}$ Department of Medicine, Hamad Medical Corporation, Doha, Qatar ${ }^{5}$ Business Intelligence Unit, Hamad Medical Corporation, Doha, Qatar ${ }^{6}$ Department of Laboratory Medicine, Hamad Medical Corporation, Doha, Qatar ${ }^{7}$ National Ambulance Service, Hamad Medical Corporation, Doha, Qatar ${ }^{8}$ Department of Medicine, Weill Cornell Medical College, New York, Doha, United States, Qatar

Dissemination declaration Dissemination to study participants or patient organisations is not possible/applicable.

Contributors Drafting of the manuscript: HMAK, HFAR, LJA-R, RB and AAB; data acquisition: AAB, AAK, MAT, AL, ZAK, SAM, HEA, RO, MAM and A-BA-S; laboratory testing and reporting: EAK and PC; study design: HMAK, HFAR, LJA-R, RB and AAB; data analysis: AAB; data interpretation: HMAK, AAB, HFAR, LJA-R and RB; critical appraisal and review: all authors.

Funding The authors have not declared a specific grant for this research from any funding agency in the public, commercial or not-for-profit sectors.

Competing interests None declared.

Patient and public involvement statement There was not patient or public involvement in the design, conduct or reporting of this study.

Patient consent for publication Not required.

Ethics approval The Institutional Review Board at Hamad Medical Corporation approved this study with an expedited status due to the emergency pandemic status of the COVID-19 outbreak (MRC-05-011).

Provenance and peer review Not commissioned; externally peer reviewed.

Data availability statement All data relevant to the study are included in the article or uploaded as supplementary information. No additional data are available.

Supplemental material This content has been supplied by the author(s). It has not been vetted by BMJ Publishing Group Limited (BMJ) and may not have been peer-reviewed. Any opinions or recommendations discussed are solely those of the author(s) and are not endorsed by BMJ. BMJ disclaims all liability and responsibility arising from any reliance placed on the content. Where the content includes any translated material, BMJ does not warrant the accuracy and reliability

Table 5 Relative change in people visiting areas of common interest in the state of Qatar (comparison period 3 January 2020 6 February 2020)

\begin{tabular}{lllll}
\hline & Qatar 29 March (\%) & Qatar 5 April (\%) & Qatar 11 April (\%) & Qatar 17 April (\%) \\
\hline Retail and recreation & -51 & -50 & -63 & -69 \\
Grocery and pharmacy & -25 & -21 & -35 & -44 \\
Parks & -34 & -35 & -48 & -64 \\
Transit stations & -52 & -52 & -60 & -68 \\
Workplaces & -31 & -36 & -39 & -38 \\
Residential & +22 & +24 & +23 & +21 \\
\hline
\end{tabular}


of the translations (including but not limited to local regulations, clinical guidelines, terminology, drug names and drug dosages), and is not responsible for any error and/or omissions arising from translation and adaptation or otherwise.

Open access This is an open access article distributed in accordance with the Creative Commons Attribution Non Commercial (CC BY-NC 4.0) license, which permits others to distribute, remix, adapt, build upon this work non-commercially, and license their derivative works on different terms, provided the original work is properly cited, appropriate credit is given, any changes made indicated, and the use is non-commercial. See: http://creativecommons.org/licenses/by-nc/4.0/.

\section{ORCID iDs}

Laith J Abu-Raddad http://orcid.org/0000-0003-0790-0506

Adeel Ajwad Butt http://orcid.org/0000-0002-1118-1826

\section{REFERENCES}

1 Zhu N, Zhang D, Wang W, et al. A novel coronavirus from patients with pneumonia in China, 2019. N Engl J Med 2020;382:727-33.

2 Chen N, Zhou M, Dong X, et al. Epidemiological and clinical characteristics of 99 cases of 2019 novel coronavirus pneumonia in Wuhan, China: a descriptive study. Lancet 2020;395:507-13.

3 Huang C, Wang Y, Li X, et al. Clinical features of patients infected with 2019 novel coronavirus in Wuhan, China. Lancet 2020;395:497-506.

4 Wang D, Hu B, Hu C, et al. Clinical characteristics of 138 hospitalized patients with 2019 novel coronavirus-infected pneumonia in Wuhan, China. JAMA 2020;323:1061.

5 Lu R, Zhao X, Li J, et al. Genomic characterisation and epidemiology of 2019 novel coronavirus: implications for virus origins and receptor binding. Lancet 2020;395:565-74.

6 Phan LT, Nguyen TV, Luong QC, et al. Importation and human-tohuman transmission of a novel coronavirus in Vietnam. N Engl J Med 2020;382:872-4.

7 Young BE, Ong SWX, Kalimuddin S, et al. Epidemiologic features and clinical course of patients infected with SARS-CoV-2 in Singapore. JAMA 2020;323:1488.

8 Holshue ML, DeBolt C, Lindquist S, et al. First case of 2019 novel coronavirus in the United States. N Engl J Med 2020;382:929-36.

9 Lescure F-X, Bouadma L, Nguyen D, et al. Clinical and virological data of the first cases of COVID-19 in Europe: a case series. Lancet Infect Dis 2020;20:697-706.
10 Oksanen A, Kaakinen M, Latikka R, et al. Regulation and trust: 3-month follow-up study on COVID-19 mortality in 25 European countries. JMIR Public Health Surveill 2020;6:e19218.

11 World population review, 2020. Available: https://worldpopulationr eview.com/countries/qatar-population/

12 Wu C, Chen X, Cai Y, et al. Risk factors associated with acute respiratory distress syndrome and death in patients with coronavirus disease 2019 pneumonia in Wuhan, China. JAMA Intern Med 2020;180:934.

13 Zhou F, Yu T, Du R, et al. Clinical course and risk factors for mortality of adult inpatients with COVID-19 in Wuhan, China: a retrospective cohort study. Lancet 2020;395:1054-62.

14 Nour M, Alhajri M, Farag E, et al. How do the first days count? A case study of Qatar experience in emergency risk communication during the MERS-CoV outbreak. Int J Environ Res Public Health 2017;14:1597.

15 Farag E, Nour M, Islam MM, et al. Qatar experience on one health approach for middle-east respiratory syndrome coronavirus, 20122017: a viewpoint. One Health 2019;7:100090.

16 CDC. Contact tracing for COVID-19, 2020. Available: https://www. cdc.gov/coronavirus/2019-ncov/php/contact-tracing/contacttracing-plan/contact-tracing.html

17 ThermoFisher. TaqPath COVID-19 Combo kit, 2020. Available: https://assets.thermofisher.com/TFS-Assets/LSG/manuals/ MAN0019372_TaqPathCOVID-19_Kit_Australia_NZ_IFU.pdf

18 Roche. Cobas ${ }^{\circledR}$ SARS-CoV-2 test, 2020. Available: https://www. diagnostics.roche.com/us/en/products/params/cobas-sars-cov-2test.html

19 WHO. Clinical management of severe acute respiratory infection when COVID-19 disease is suspected, 2020. Available: https://www. who.int/publications/i/item/clinical-management-of-covid-19

20 GOOGLE. COVID-19 community mobility reports, 2020. Available: https://www.google.com/covid19/mobility/

21 Omrani AS, Almaslamani MA, Daghfal J, et al. The first consecutive 5000 patients with coronavirus disease 2019 from Qatar; a nation-wide cohort study. medRxiv 2020. DOI: 10.1101/2020.07.15.20154690.

22 WHO. Archived: WHO timeline - COVID-19, 2020. Available: https:// www.who.int/news-room/detail/08-04-2020-who-timeline---covid19

23 Worldometer. Coronavirus updates, 2020. Available: https://www. worldometers.info/coronavirus/?utm_campaign=homeAdTOA 